folk/ed. 2021; 27(2): 581-596

DOI: $10.22559 /$ folklor. 1625

Derleme makalesi /compilation article

\title{
Kosova Türklerinde Sevimli (Hipokoristik) Adlar
}

\author{
Hypocoristic Names at Kosovo Turks
}

\author{
İsa Sülçevsi* \\ İsa Memishi**
}

$\ddot{O} \mathbf{z}$

Kosova Türklerinin yaşadıkları kültür coğrafyasında yaygın olarak kullanılan sevimli (hipokoristik) adlar, kültürel etkileşim yoluyla Kosova Türklerinde de normal kullanım alanı bulmuştur. Sultan İkinci Murat zamanında Anadolu'dan iskân ettirildiği düşünülen Kosova Türklerinin etnik ve kültür kökeni Anadolu'ya dayanır. Bu nedenle Kosova Türklerinin kültür ve folklorunda Anadolu'dan getirdikleri mirasın izleri görülür. Bu mirasın izlerini özel ve kamusal yaşamın her alanında görmek mümkündür ve buna ilişkin hatırı sayılır araştırma yapılmıştır. Kosova Türkleri bu kültürel mirası buralara yerleşip bu toprakların yerli unsuru haline geldikten sonra yerel kültür ve folklor unsurlarılla zenginleştirmiş̧tir. Henüz araştııılmamış olan Kosova Türklerine ilişkin folklorun bu yönü araştırılmaya değerdir. Kültürel etkileşimin sonucunda folklorik bir özellik olarak kişi adlarına sevimli (hipokoristik) ad üretme geleneği gelişmiş̧ir.

Geliş tarihi (Received): 23.06.2020 - Kabul tarihi (Accepted): 22.03.2021

* Yrd. Doç. Dr. Kosova Priştine Üniversitesi Filoloji Fakültesi Şarkiyat Bölümü. Kosovo Pristina University Faculty of Philology Department of Oriental Studiesisa.sulcevci@uni-pr.edu, ORCID 0000-0001-6537-1919

** Doç. Dr. Kosova Priştine Üniversitesi Filoloji Fakültesi Şarkiyat Bölümü.(Kosovo Pristina University Faculty of Philology Department of Oriental Studies) isa.memishi@uni-pr.edu, ORCID 0000-0002-4232-0681 
Kosova Türklerinin adbilimi ile ilgili çalışmalar sınırlıdır fakat hem terim hem olgu olarak sevimli (hipokoristik) ad, çalışılmış bir konu değildir.

Çalışmamızda terimin anlamı ve kökeni hakkında kısaca durulmuştur. Devamında Kosova Türklerinde sevimli (hipokoristik) ad yapma yolları hakkında bilgilere ve cinsiyete bağlı olarak yaygınlık kazanmış sevimli (hipokoristik) ad örneklerine yer verilmiştir. Bu çalışmada Balkan Türkleri kişi adları açısından önem arz eden bu sözcüklerin nereden geldiklerine 1şık tutulmaya çalışılmıştır.

Anahtar sözcükler: sevimli (hipokoristik) ad, adbilim, kişi adları, soyadları, Kosova Türkleri

\begin{abstract}
Hypocoristic names, which are widely used in the cultural geography where Kosovo Turks live, have likewise found normal use among Kosovo Turks through cultural interaction. The ethnic and cultural origins of the Kosovo Turks is based on Anatolia, as it is believed to have been settled from Anatolia during the reign of Sultan Murat II. Due to this, in their culture and folklore, there can be noticed traces of the heritage brought from Anatolia. It is possible to see the traces of this heritage in all areas of private and public life, therefore, there have been done considerable research on the issue. After settling in these lands and becoming the indigenous component of the same, Kosovo Turks enriched this initial cultural heritage with local cultural and folklore elements. This aspect of the Kosovo Turks folklore has not yet been explored and is worth researching. As a result of cultural interference, there have been developed a tradition of hypocoristic creation of personal names as a folkloric feature.

Studies on the onomastics of Kosovo Turks are limited, but not inexistent. Nevertheless, hypocorism is not a studied subject, both as a term and as a phenomenon.

In our study, we strived to briefly discuss the meaning and origin of the term. Subsequently, we shared information on ways to create hypocorisms and included examples of common hypocoristic names depending on gender. We tried to shed light on where these words, as important for Balkan Turkish anthroponomy, derive from.
\end{abstract}

Keywords: hypocoristic, onomastics, anthroponyms, patronymics, Kosovo Turks

\title{
Extended summary
}

Turks, who are known to have an uninterrupted history of six centuries in Western Balkans, and therefore also in Kosovo, are part of the indigenous people of this area, and have an authentic identity in this respect. For this reason, it is important to develop a perspective on Kosovan Turks in which this authenticity will come to the forefront in studies conducted on language, 
literature, folklore, and culture. The present study discusses a characteristic that has a place in the anthroponyms and patronyms of Kosovan Turks.

Hypocoristic refers to the nouns used to address a person, are made of full forms of personal nouns and used in colloquial speech. The term "hypocoristic nouns", which is widely used in Latin and Slavic cultures, and used to express sincerity or as diminutive suffix, is rarely known in the Turkology literature. The term is sometimes, synonymously, referred to as diminutive nouns in Western sources.

The word "hypocoristics" was derived from the Greek word meaning "imitation of a child's speech". The imitation of a child's speech is the result of an adult's effort to communicate with a child. Adults use hypocoristics words when they communicate with a child who has just started speaking or has not yet. Sometimes, such words can be derived from the abbreviation of a word, and sometimes words consisting of completely different sounds are used.

The scope of hypocoristic nouns is, but not limited to, personal nouns. Hypocoristic nouns can be used as nouns of kinship, even as nouns that refer to some professions and sociocultural classes. Based on the sources reviewed about the languages spoken in Kosovo, it was noted that hypocoristic nouns are treated as lexemes in Slavic grammar books, and the affixes that make up these lexemes are discussed within the context of derivational affixes. Hypocoristic derivative affixes are also included in sources related to the Albanian language. Although hypocoristics and diminutive affixes are discussed under the same heading in some sources, they are differentiated noticeably in other sources.

The majority of the population who speak Turkish as their mother tongue or ambient language in Kosovo live in a multilingual and multicultural urban environment. The structure and construction of hypocoristic nouns that are commonly used by Kosovan Turks were determined based on Slavic sources. The Slavic preference for resources comes from the opinion that these nouns used by Kosovan Turks resemble Slavic forms.

Hypocoristic nouns can be derived based on personal nouns, or from the colloquial speech or adjectives used for addressing people. Hypocoristics derived from personal nouns and kinship nouns are derived in three ways: (1) By abbreviating the exact form of the personal and kinship nouns, (2) by imitating a child's speech, and (3) by adding diminutive suffix to personal nouns.

The first way is to shorten the nouns and add hypocoristic suffixes or with an inspired version of the basic form of the personal noun. To produce hypocoristic nouns, the suffixes $-a /-i /-o$, $-k a /-k i /-k o$ and $-u s ̧$ are used. Among these, $-a /-i /-o$ and $-k a /-k i /-k o$ are hypocoristic derivatives in Slavic; and $-u s$ appears to be borrowed from Albanian. The examples of hypocoristics produced with these suffixes are as follows:

(The examples made with - a suffix)

$\mathrm{Ab}-\mathrm{a}<$ abla, sal-a $<$ Saliha, ism-a $<$ İsmet.

(The examples made with $-i$ suffix)

Os-i<Osman, Suz-i $<$ Suzan, Ber-i $<$ Behiye / Bahriye, ac-i<amca, Seb-i $<$ Sebahat, Ek-i $<$ Ekrem, Muk-i<Mukaddes, Mak-i<Makfire, Şuk-i<Şükran / Şükriye, Fat-i<Fatime.

(The examples made with -o suffix) 
Sad-o $<$ Sadettin / Sadullah, Ram-o $<$ Ramiz / Ramadan (Ramazan), Al-o $<$ Ali / Alaeddin, ac$\mathrm{o}<$ amca, Sül-o $<$ Süleyman, Nim-o $<$ Nimetullah, ab-o $<$ abla, Beyt-o $<$ Beytullah, Sab-o $<$ Sabit $/$ Sabri / Sabriye, Gün-o $<$ Güner, Gül-o $<$ Gülten, Müc-o $<$ Mücahit, Muz-o $<$ Muzaffer, Erd-o $<$ Erdoğan, Sel$\mathrm{o}<$ Selahattin, Bat-o $<$ Batiyar (Bahtiyar) / Batişa (Bahtışah), bac-o $<$ bacanak.

(The examples made with -ka suffix)

Neb-ka<Nebahat, Ay-ka<Aynur / Ayhan, Cül-ka<Gülsüm / Güllü / Gülnaz, Züb-ka<Zübeyde, Nur-ka<Nuriye / Nuray / Nuran, Nu-ka<Nuriye / Nuray / Nuran, Züm-ka<Zümrüt, Hüs$\mathrm{ka}<$ Hüsamettin/Hüseyin, Bes-ka $<$ Besim.

(The examples made with -ke suffix)

Tas-ke $<$ Tasin, Da-ke $<$ Daver, Ray-ke $<$ Raif, Samke $<$ Saime.

(The examples made with -ki suffix) Ce-ki<Celal / Celadin (Celaleddin) / Ceylan, Naski<Nazan, O-ki<Orhan / Oktay, Züki<Züleyha, Pe-ki<Perihan, Ne-ki<Nezir, Neşet, Nermin, Buki<Burhan, Tu-ki<Türkan, Su-ki<Sunay, Şe-ki<Şerif / Şefik, Hay-ki<Hayriye.

(The examples made with -ko suffix) Set-ko<Sedat, day-ko<day1, tet-ko<teyze, nisko<Nizayet (Nezahat), Far-ko<Faredin (Fahrettin), Şaç-ko<Şaçir (Şakir), Tas-ko<Tasin (Tahsin), Can-ko $<$ Canan / Cansel, Sal-ko $<$ Salih, Zu-ko $<$ Zülfikar.

(The examples made with -uş suffix)

Al-uş $<$ Ali, İbr-uş $<$ İbrahim, Seb-uş $<$ Sebaedin / Sebaydin (Sabahattin), İlm-uş $<$ İlmi (Hilmi), Kadr-uş $<$ Kadri, Beyt-uş $<$ Beytullah, Abd-uş<Abdi / Abdullah, Nak-uş $<$ Nakiye, Mak-uş / Mik-uş / Mek-uş $<$ Makfire, Mik-uş<Milaim (Mülayim), Necm-uş<Necmi / Necmettin, Hayr-uş $<$ Hayri / Hayrettin, bab-uş<baba, tet-uş<teyze, hal-uş<hala, Bayr-uş<Bayram.

Albeit limited, hypocoristics can also be done with the "-çe" suffix, which was borrowed from Persian and articulated Turkish.

\section{Bayçe< Bayram, Çamçe< Çamil (Kâmil).}

It is not possible to say or determine that the second type of hypocoristic nouns, which are mostly produced by cropping the word and using an inspired form of the basic form of the noun, have a morphophonetic structure. Such hypocoristic nouns are made without applying any rules. Sometimes they are made by adding hypocoristic suffixes to the middle or the last syllable of a noun as two or more syllables.

Tsani $<$ Hasan, Dulo $<$ Abdullah, Dino $<$ Şerafettin / Hayrettin, Emi $<$ Elmas, Buşi $<$ Neb-uş / Buşka $<$ Neb-uş-ka $<$ Nebahat, Dano $<$ Ramadan, Mani / Manke $<$ Neriman / Keriman, Limi $<$ Selim, Tsufo $<$ Yusuf, Utsi $<$ Yusuf, Muyo $<$ Muhammet / Muharrem, Deti $<$ Saadet, İbadet, Mino $<$ Emine, Lido $<$ Mevlüde, Gipa $<$ Nagip, Nepo $<$ Zeynep, Zepo $<$ Zeynep, Meto $<$ Mehmet / Ahmet, Tafo $<$ Mustafa, Meri $<$ Meyrem (Meryem), Demo $<$ Adem.

The third type is hypocoristic nouns made by imitating the speech of a child or a baby. It is not possible to predict what these hypocoristic nouns will turn out to be. Also, it is difficult to determine which noun or hypocoristic noun they originate from 


\section{Giriş}

Çeşitli tarih kaynakları Türklerin Balkanlar'a ilk gelişlerini Osmanlı öncesi döneme bağlamaktadır. Ancak günümüzde Batı Balkanlar'da yaşayan Türklerin dil, edebiyat, kültür ve folklor birikimlerinde Osmanlı öncesi dönemden kaldığı ortaya konmuş zengin bir mirastan bahsetmek mümkün gibi görünmemektedir. Özellikle Kosova'da yaşayan Türkler bakımından böyle bir şeyin söz konusu olduğunu söyleyebilmek için elde geçerli deliller bulunmamaktadır. Şu hâlde Kosova Türklerinin birikiminin Anadolu'nun kültür dairesinden getirdikleri özelliklerin üzerine altı asırlık süreçte bu topraklarda ekledikleri özelliklerin toplamından oluştuğu söylenebilir. Altı asırlık süreçte yerel düzeyde oluşturulan bu birikim, Kosova Türklerinin özgün yaratımlarının yanı sıra aynı ortamı paylaştıkları diğer milletlerin birikimlerinden de aktardıkları özellikleri içine alır. Bu birikimin hangi özelliklerinin özgün yaratımlar hangilerinin aktarılmış unsurlar olduğunu tespit etmek için karşılaştırmalı çalışmalar yapılmalıdır. Kosova Türklerinin kültürel birikimlerine ilişkin yapılmış olan çalışmalarda karşılaştırmalı yöntemlerin uygulandığı pek söylenemez. Şimdiye kadar yapılan çalışmalarda daha çok folklorik özelliklerin tespiti üzerinde durulmuştur.

Batı Balkanlar ve bu çerçevede Kosova'da altı asırlık kesintisiz bir geçmişi olduğu bilinen Türkler, bu bölgenin yerli nüfusunun bir parçasıdır ve bu nedenle özgün bir kimliğe sahiptir. Dolayısıyla Kosova Türkleri hakkında dil, edebiyat, folklor, kültür vb. alanlarla ilgili çalışmalarda bu özgünlüğün öne çıkacağı bir bakış açısı geliştirilmesi önem arz eder. Bu çalışmada Kosova Türklerinin kişi adları (antroponimi) ve soyadlarının (patronimi) kültüre has özellikleri ele alınarak incelenmiştir.

\section{Sevimli ${ }^{1}$ ad (hipokoristik) terimi}

Hipokoristik, kişi adlarının tam şekillerinden yapılmış ve aile içi veya arkadaşlık

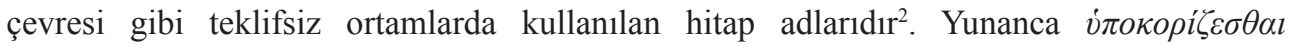
(hypokorizesthai)'den türeyen bu terim çocuk konuşması taklidi anlamına gelmektedir (Bosanac, 2009, s. 5). Anglosakson (Tunçdemir, 2015), Latin ve Slav kültürlerinde yaygın olarak kullanılan ve samimiyet ya da küçültme adları olarak da ifade edilen sevimli (hipokoristik) adlar terimi Türkoloji literatüründe az bilinen bir terimdir. Bu terim Batılı kaynaklarda da bazen küçültme ekiyle yapılan (deminutif) ad şekilleriyle eş anlamlı olarak ele alınmaktadır ${ }^{3}$. Ancak bu çalışmada ele alınan sevimli (hipokoristik) ad örnekleri Türk kültüründe bilinen Ömercik, Mehmetçik, Ayşecik gibi sevgi ve şefkat ifade eden kişi adı şekillerinden farklıdır.

Aksan (2000: 116) Hz. Yahya'nın adının Almancadaki şeklinin “Johannes, Johann, kısalmış biçimiyle Hans, kimi bölgelerde Hen ve Hensel" olduğunu belirttiği yerde "kısalmış biçim” ifadesini kullanmıştır. Sarı (2020, 98) Zeynoş (<Zeynep), İboş (<İ̉brahim), Mıstık (<Mustafa), Nazmik (<Nazmiye) gibi örnekler için kısaltmalı özel adlar tanımlamasını tercih etmiştir. Türkçede küçültmeyi ele aldığı eserinde Sarı (2020: 96), -ş ekinin özel adlara getirilmesinin işlevini açıkladığı yerde seslik değişim ve kısaltma ifadesini kullanmıştır.

Aksan, kişi adlarının sevimli (hipokoristik) ad tanımına benzer nitelikte olan biçimlerini 
yukarıda belirtilen "kısalmış biçim”in yanı sıra “ön adların değiştirilmiş biçimleri”" şeklinde adlandırmıştır. Aksan, “ön adların değiştirilmiş biçimleri”ni şu şekilde açıklamıştır:

"Her dilde olduğu gibi Türkçede de adların, özellikle ön adların çeşitli etkenlerle değiştirilmiş biçimleri de vardır. Kimi zaman ünlü uyumu kurallarına aykırı düşen bu örnekler, çoğu kez, dilde en az çaba yasasına (dilde ekonomiye) de örnek oluştururlar: Mustafa yerine Mıstık, Ibrahim yerine İbo ya da İbiş; Fatma yerine Fatoş, Zeynep için Zeyno, Emine için Emiş ya da Emoş... gibi. Bunlardan bir bölümü - değişik kullanım oldukları halde- ön ad niteliği kazanmıştır" (Aksan, 2000: 123).

Ancak sevimli (hipokoristik) adlar her zaman kişi adlarının basit bir şekilde kısaltılmasından oluşmazlar. Kişi adlarının kısaltılmış şekillerinin yanı sıra kırpma 4 yoluyla ve farklı ses değişmelerine uğramış şekillerinden ve bazı eklerden oluşabilmektedir. Aliş/ Aluş<Ali, Meto <Ahmet, Dulo<Abdullah, Patuka $<$ Fat-uş-ka (Fatime/Fatıma) gibi. Nitekim Britannica'nın hypkorsitic name $e^{5}$ maddesinde kişi adlarının "genelde kısaltılmış veya başka şekilde değiştirilmişmiş" şekilleri olduğu belirtilmiştir.

Hipokoristik, lakap veya mahlas olabilir mi sorusu akla gelebilir. Güncel Türkçe Sözlük'te lakap 6 maddesi "Bir kimseye, bir aileye kendi adından ayrı olarak sonradan takılan, o kimsenin veya o ailenin bir özelliğinden kaynaklanan ad" olarak verilmiştir. Kubbealtı Lugati'nde lakap ${ }^{7}$ maddesi "1. Bir kimse veya âileye herhangi bir münâsebetle asıl adından başka sonradan takılan ad, takma ad. 2. Osmanlı devrinde resmî yazışmalarda rütbe sâhipleri için rütbelerine göre kullanılan rif'atlü, izzetlü gibi unvan" şeklindedir. TDK Güncel Sözlük’te mahlas ${ }^{8}$, "takma ad” olarak tanımlanmıştır. Kubbealtı Lügati’nde ise mahlas " "1. Şâirlerin manzum eserlerinde kullandıkları takma ad. 2. Bir kimsenin ismine eklenen ikinci isim.” şeklinde verilmiştir. Bu tanımların sevimli (hipokoristik) ad tanımından farklı oldukları anlaşılıyor. Hipokoristik terimi için İmer ve diğerleri (2013: 228) Türkçe bir karşılık olarak "sevimli” terimini kullanmışlardır. Bu çalışmada da hipokoristik karşılığı olarak sevimli terimi benimsenmiştir.

Hipokoristik kelimesinin çocuk konuşması taklidi anlamında Yunanca bir türetme olduğu yukarıda belirtildi. Çocuk konuşması taklidinin bir yetişkinin bir çocukla iletişim kurma çabasının bir sonucu olduğunu ileri sürülebilir. Yetişkinler konuşmaya yeni başlamış olan veya henüz konuşmayan bir çocukla iletişim kurarken hipokoristik yapılı sözcükler kullanır. Bu sözcükler bazen bir kelimenin kısaltılmış şeklinden yapılabildiği gibi bazen de tamamen farklı seslerden oluşan sözcükler kullanılır. Bıcı bıcı yapmak bir çocuğun küvette yıkanması için kullanılan bir ifadedir. Kosova Türkleri bazen Türkçe sözcüklerden kısaltma yoluyla sevimli (hipokoristik) kelimeler yaparlar. Bunka / butsi (burun), kuli (kulak), dika (diş) gibi. Bazen de tamamen farklı seslerden oluşan sevimli kelimeler (hipokoristikler) kullanırlar. Toti (el), pati (ayak), pupa (karın, göbek), papa (gezmeye çıkmak), çupa çupa (yıkanmak), kuta (köpek), beka (koyun, kuzu), digıdıg (at), tika (tavuk), bu (su), cica (bir nesnenin sicak olduğu uyarısı), pum (düşme veya düşüp yaralanma uyarısı), apiş (bir nesnenin kaybolduğunu 
söyleme) gibi. Bu son örneklerden bazıları Kosova'da konuşulan diller arasında yer alan Arnavutça veya Sırpçadaki bazı yansıma sözcüklerden yapılmışlardır. Buraya kadar yapılan açıklamalar ve bu açıklamaları destekleyen örnekler "adların kısaltılmış ve farklı ses değişmelerine uğramış şekli” için hipokoristik teriminin kullanılması hususunda yeterli ve geçerli gerekçeler olmakla birlikte İmer ve diğerlerinin (2013) verdikleri sevimli karşılığı, bağlamın imkân verdiği ölçüde, parantez içerisinde hipokoristik ile birlikte kullanılmasında karar kılınmıştır. Ancak bazı durumlarda sadece hipokoristik kelimesi kullanılmıştır.

Tanımdan anlaşılacağı üzere sevimli (hipokoristik) adların kapsamı kişi adları olmakla birlikte, bununla sınırlı değildir. Akrabalık adlarına, hatta bazı meslekleri ve sosyokültürel sınıfları karşılayan adlara da sevimli (hipokoristik) adlar yapıldı̆̆ı görülmektedir. Kosova'da konuşulan dillerle ilgili taranan kaynaklardan Slavca ${ }^{10}$ gramer kitaplarında sevimli (hipkoristik) adların sözlük birimi (leksem) (Halilović, Tanović ve Šehović, 2009: 169) olarak muamele gördüğü ve bu sözlük birimleri yapan eklerin yapım ekleri içerisinde ele alındığı görünmektedir. (Barić ve diğerleri, 1997: 329) Hırvatçada küçültme ve sevimlinin yani deminutiv ile hipokoristiğin anlam bilimsel açıdan örtüştüğü ve ayrıştığı yönleri Ćužić ele almış ve "deminutif prensipte hipokoristik anlama sahip olabiliyorken, hipokoristik belli ölçüde deminutif ve dolayısıyla küçültme anlamı barındırabilir" (Ćužić, 2017) tespitini ortaya koymuştur. Kosova Türkçesinin ilişkide olduğu Arnavutça ile ilgili kaynaklarda da sevimli (hipokoristik) ad yapma eklerine yer verilir. (Xhuvani ve Çabej, 1962) Bahse konu bu kaynaklarda sevimli (hipokoristik) yapılı adlar küçültme (deminutif) adlarından ayrılırlar. Bazı kaynaklarda sevimli ile küçültme (hipokoristik ile deminutif) yapma ekleri aynı başlık altında gösterilmekle birlikte (Piper ve Klajn, 2014: 226) diğer bazı kaynaklarda bu ayrım açık bir şekilde yapılır (Demiraj, 2002: 144).

\section{Kosova Türklerinde sevimli (hipokoristik) ad verme eğilimleri}

Kosova Türkleri Osmanlı idaresi zamanlarında Anadolu'dan iskân ettirilmiş Türklerden olduklarından ad verme gelenekleri Türk-İslam geleneklerine uygundur. Dolayısıyla Abdürrahman'ın (2004) belirttiği şekilde “Türkler İslamiyet'i kabul ettikten sonra Türklerin, 'ismin gerçek ve kutsallığına inanmak' anlayışı ile Arapların, 'isim akideciliği' (inanc1) birleştirilerek daha kuvvetli bir gelenek haline dönüştürülmüştür”. Bu nedenledir ki Kosova'da anne babalar veya nine ile dedelerin bir kısmı, özellikle daha muhafazakâr olanları, kendi çocuklarına veya torunlarına sevimli (hipokoristik) ad uydurulmasından çok hoşnut olmazlar.

Kosova Türklerinde sevimli (hipokoristik) adların kullanılmasında kültürel etkileşimin etkili olduğunu söylemek mümkün. Türkiye'de adların bu şekillerinin kullanılması ise en az çaba yasasına bağlanmaktadır. Aksan (2000: 173) “ön adların değiştirilmiş biçimlerinin” en az çaba yasasının bir sonucu olduklarını ileri sürmektedir. Ancak Karahan (2009: 19) "Fatoş, Emoş, Memoş, Mıstık gibi değiştirmelerin (...) kolay söyleme, en az çaba gösterme eğilimi yanında, sevgi ve şefkat ifade etme ihtiyacının, özellikle şehirlerde modernleşme hevesinin etkili olduğu" görüşündedir. 
Kosova'da Türkçeyi anadili veya ortam dili olarak konuşan nüfusun ekseriyeti çok dilli ve çok kültürlü şehir ortamında ikamet eder. Şehir ortamına rağmen ataerkil aile yapısını son dönemlere kadar muhafaza edebilmiş olan Kosova Türklerinin erkeklerinin, daha etkin oldukları mahalle ve meclislerin karma kültürlerinden, kadınlara kıyasla daha fazla etkilendikleri unutulmamalıdır. Sevimli (hipokoristik) ad üretme de geçen asrın doksanlı yıllarından önceki dönemlerde Kosovalı Türk erkeklerinde daha yaygın görülürdü. Ancak, son dönemlerde, özellikle şehirlerde yaşayan Kosovalı Türklerde meydana gelen bazı sosyokültürel gelişme ve değişmeler sonucunda kadınların sosyal hayattaki konumu değişmiştir. Bunun bir yansıması olarak kadın ve kızlara da sevimli (hipokoristik) adların daha yüksek oranda üretilmeye başlandığı görülmektedir.

Türkçe edebi kaynaklarda geçen Memo, Cano, Maho gibi seslenme adları dışında televizyon dizilerinde tontiş, aşkito, caniko, kankal kardo gibi sevimli (hipokoristik) yapılı adların dar bazı çevrelerde (köy ortamı, genç arkadaş çevresi, genç sevgililer arasında vb.) kullanılması bunun aslında Türk kültürüne tamamen yabancı bir olgu olmadığını ortaya koyar niteliktedir. Ancak bu adlar, muhtemelen kültürel hassasiyetlerden dolayı, belli bir çevrenin sınırları içerisinde kalmış ve yaygınlık kazanamamıştır.

Kosova Türklerinde yaygın olarak kullanılan sevimli (hipokoristik) adların yapısı ve yapılışı, Slavca kaynaklara dayanılarak tespit edilmeye çalışılmıştır. Slavca kaynak tercihi, Kosova Türklerinde görülen bu adların, kültürel etkileşim sonucunda Slavca şekillerine benzediğine ilişkin kanaatten ileri gelmektedir.

Slav dili olan Boşnakçayı konuşan Müslüman Boşnaklar çoğunlukla Müslüman kişi adlarını tercih ederler. Boşnaklarda Türkçe üzerinden kabul görmüş kişi adlarına, akrabalık adlarına, hatta "beša"<"bešika" (beşik), "ćato"<"ćatip" (kâtip) örneklerinde olduğu gibi bazı nesneleri veya meslekleri karşılayan cins adlara bile sevimli (hipokoristik) adlar üretilmiştir. Boşnak araştırmacı Şkaliç’in (Škaljić, 1966) Sırp-Hırvatçadaki Türkizmalar adlı sözlüğünde toplam 209 adet kişi adı, meslek adı ve nesne adına yapılmış sevimli (hipokoristik) ad tespit etmiştir. Meslek adı olan "ćato" gibi örnekler günümüz Sırpça ve Hırvatça dillerinde kullanılmaya devam etmektedir. Kişi adları hipokoristikleri ise Müslüman adı oldukları için sadece Müslüman Boşnaklarda kullanılır.

\section{Sevimli (hipokoristik) ad yapma yolları}

Sevimli (hipkoristik) adlar kişi adlarından hareketle yapılabildikleri gibi, akrabalık ve teklifsiz konuşmada kullanılan seslenme ad veya sıfatlarından da yapılabilmektedir.

Kişi adları ve seslenme ya da akrabalık adlarından türetilen hipokoristikler şu üç şekilde yapilırlar:

1. Kişi ve akrabalık adlarının tam şekillerinin kısaltılması yoluyla

2. Çocuk konuşması taklit edilerek

3. Kişi adlarına küçültme ekleri getirilerek

Hipokoristikler kullanım amaçlarına göre de iki sınıfta değerlendirilebilir: 
1. Teklifsiz ortamlarda sevgi, şefkat ve samimiyet bildiren olumlu anlamlı hipokoristikler;

2. Hakaret amaciyla kullanılan hipokoristikler.

\subsection{Kişi adlarının kısaltılması}

Adlar kısaltılıp hipokoristik yapma ekleri getirilerek veya kişi adının temel şeklinden esinlenerek yapılan şekillerdir. Hipokoristik yapmak için -a/-i/-o, -ka/-ki/-ko (Halilović, Tanović ve Šehović, 2009: 71), -uş (Demiraj, 2002: 286) ekleri kullanılır. Elöve ${ }^{12}$ (Deny, 2012: 487-488) Rumeli'de oş, ko, o, $l$ gibi tahbib eklerini tespit ettiğini belirtir. Bu ekler çok heceli kişi veya akrabalık adlarının çoğunlukla ünsüzle biten ilk hecelerinin arkasına getirilerek yapılır.

Bu eklerden -a/-i/-o, -ka/-ki/-ko Slavcada hipokoristik ad yapma ekidir (Barić ve diğerleri, 1997: 329). $a$ - ve - $i$ ekleri cinsiyet farkı olmaksızın kişi adlarından sevimli (hipokoristik) adlar yapmaya yarar. -o eki erkek kişi adlarından sevimli (hipokoristik) adlar yapar. -ka eki kadın kişi adları, kadınlar için kullanılan akrabalık ve meslek adlarından sevimli (hipkoristik) adlar yapmak için kullanılır. -ko eki erkek kişi adları, erkekler için kullanılan akrabalık ve meslek adlarından sevimli (hipkoristik) adlar yapmak için kullanılır (Barić ve diğerleri, 1997: 329).

-ko eki Arnavutçada ağız kullanımlarında dajko (dayı), vëllaçko (birader) (Demiraj, 2002: 144) örneklerinde sınırlı kullanım alanı bulmuştur. Aynı ek Sırpçada hipokoristik yapım eki başlığı altında ele alınır (Piper ve Klajn, 2014: 70).

-ki eki Slavcada baka-baki<baba (nine), seka-seki<sestra (kızkardeş), koka-koki<kokoška (tavuk) gibi örneklerde -ka eki ile yapılmış sevimli (hipokoristik) adların Slavcada datiflokatif durumda aldığı şekilden gelme ihtimali vardır.

Kosova Türklerinde de bu ekler kullanılır. Bunlardan sadece - uş eki Arnavutçadan alınmış görünmektedir. Bu ek de zaten daha önceden yapılmış bir sevimli (hipokoristik) ada daha fazla yakınlık ve sevgi anlamı katmak için kullanılır. Yukarıda belirtildiği şekilde Slavcada kullanılan sevimli (hipokoristik) ad eklerinden bir kısmı cinsiyet kategorisini barındırırken, Kosova Türklerinde cinsiyet kategorisini barındırmazlar.

\subsection{1. -a Eki ile yapılan sevimli (hipokoristik) ad örnekleri}

Ab-a $<$ abla, sal-a $<$ Saliha, ism-a $<$ İsmet.

\subsection{2. -i Eki ile yapılan sevimli (hipokoristik) ad örnekleri}

Os-i<Osman, Suz-i<Suzan, Ber-i<Behiye / Bahriye, ac-i<amca, Seb-i<Sebahat, Ek$\mathrm{i}<$ Ekrem, Muk-i<Mukaddes, Mak-i<Makfire, Şuk-i<Şükran / Şükriye, Fat-i $<$ Fatime.

\subsection{3. -o Eki ile yapılan sevimli (hipokoristik) ad örnekleri}

Sad-o $<$ Sadettin / Sadullah, Ram-o $<$ Ramiz / Ramadan (Ramazan), Al-o $<$ Ali / Alaeddin, 
ac-o $<$ amca, Sül-o $<$ Süleyman, Nim-o $<$ Nimetullah, ab-o $<$ abla, Beyt-o $<$ Beytullah, Sab$\mathrm{o}<$ Sabit / Sabri/ Sabriye, Gün-o $<$ Güner, Gül-o $<$ Gülten, Müc-o $<$ Mücahit, Muz-o $<$ Muzaffer, Erd-o $<$ Erdoğan, Sel-o $<$ Selahattin, Bat-o $<$ Batiyar (Bahtiyar) / Batişa (Bahtışah), baco $<$ bacanak, Bedr-o $<$ Bedri/Bedrettin, Bed-o $<$ Bedriye, Beg-o $<$ bey $^{13}, \quad$ Fat-o $<$ Fatime, Bec-o $<$ Behcet, İb-o $<$ İbrahim, İbr-o $<$ İbrahim, Beç-o $<$ Beçir (Bekir), Min-o $<$ Münevver/ Münir, çop-o $<$ çolak, Caf-o $<$ Cafer, Can-o $<$ Canan, Cel-o $<$ Celal/Celalettin, Cem-o $<$ Cemal/ Cemalettin, Kem-o $<$ Kemal, Ken-o $<$ Kenan, Cev-o $<$ Cevat/Cevahir, Cül-o $<$ Cülizar (Gülizar), Cülsüm (Gülsüm), Cülnaz (Gülnaz) ${ }^{14}$, Hayr-o $<$ Hayrettin, Feyz-o $<$ Feyzullah, Fet-o $<$ Fethi, Fik-o $<$ Fikret, Hüs-o $<$ Hüseyin, İs-o $<$ İsa/İsmail, Lut-o $<$ Lütfü, Murt-o $<$ Murtaza, Remz$0<$ Remziye, Rust-o $<$ Rüstem, Sef-o $<$ Seyfettin, Şab-o $<$ Şehabettin, Şem-o $<$ Şemsettin, Zeço $<$ Zeçir (Zakir), Zekeriya.

\subsection{4. -ka eki ile yapılan sevimli (hipokoristik) ad örnekleri}

Neb-ka $<$ Nebahat, Ay-ka $<$ Aynur / Ayhan, Cül-ka $<$ Gülsüm / Güllü / Gülnaz ..., Zübka $<$ Zübeyde, Nur-ka $<$ Nuriye / Nuray / Nuran, Nu-ka $<$ Nuriye / Nuray / Nuran, Zümka $<$ Zümrüt, Hüs-ka $<$ Hüsamettin/Hüseyin, Bes-ka $<$ Besim, Çam-ka $<$ Çamile (Kâmile), Üska $<$ Üzeyir, Cem-ka $<$ Cemile, Hat-ka $<$ Hatice, Naç-ka $<$ Naciye.

\subsection{5. -ke eki ile yapılan sevimli (hipokoristik) ad örnekleri}

Tas-ke $<$ Tasin, Da-ke $<$ Daver, Ray-ke $<$ Raif, Samke $<$ Saime.

\subsection{6. -ki eki ile yapılan sevimli (hipokoristik) ad örnekleri}

Ce-ki $<$ Celal / Celadin (Celaleddin) / Ceylan, Nas-ki<Nazan, O-ki<Orhan / Oktay, Züki<Züleyha, Pe-ki<Perihan, Ne-ki<Nezir, Neşet, Nermin, Bu-ki<Burhan, Tu-ki<Türkan, Su-ki<Sunay, Şe-ki<Şerif / Şefik, Hay-ki<Hayriye.

\subsection{7. -ko eki ile yapılan sevimli (hipokoristik) ad örnekleri}

Set-ko $<$ Sedat, day-ko $<$ dayı, tet-ko $<$ teyze, nis-ko $<$ Nizayet (Nezahat), Far-ko $<$ Faredin (Fahrettin), Şaç-ko<Şaçir (Şakir), Tas-ko<Tasin (Tahsin), Can-ko<Canan / Cansel, Salko $<$ Salih, Zu-ko $<$ Zülfikar.

\subsection{8. -uş eki ile yapılan sevimli (hipokoristik) ad örnekleri}

Al-uş<Ali, İbr-uş< $<$ İbrahim, Seb-uş $<$ Sebaedin / Sebaydin (Sabahattin), İlm-uş $<$ İlmi (Hilmi), Kadr-uş<Kadri, Beyt-uş $<$ Beytullah, Abd-uş $<$ Abdi / Abdullah, Nak-uş $<$ Nakiye, Makuş / Mik-uş / Mek-uş<Makfire, Mik-uş<Milaim (Mülayim), Necm-uş<Necmi / Necmettin, Hayr-uş<Hayri / Hayrettin, bab-uş<baba, tet-uş<teyze, hal-uş<hala, Bayr-uş< $<$ Bayram.

\subsection{9. -çe eki ile yapılan sevimli (hipokoristik) ad örnekleri}


Sınırlı sayıda olmakla birlikte, Farsçadan Türkçeye geçmiş olan -çe küçültme ekiyle de hipokoristikler yapılır.

\section{Bayçe< Bayram, Çamçe< $<$ Çamil (Kâmil).}

-çe eki Makedoncada küçültme (deminutif) eki olarak yaygın kullanılır (Zakar, 2011). Kosova Türklerinin sevimli (hipokoristik) ad yapmak için kullandıkları bu ek Makedoncadan alınmış olabilir.

\subsubsection{Ek yığılmasıyla yapılan sevimli (hipokoristik) ad örnekleri}

Ek yığılması yoluyla da kimi sevimli (hipokoristik) adlar yapılır. Bu tür sevimli (hipokoristik) adlar çoğunlukla adın dişil cinsiyetine vurgu yapmak amaciyla -uş ve -ka eklerinin peş peşe kullanılmasıyla ortaya çıkar.

Neb-uş-ka $<$ Nebahat, Seb-uş-ka $<$ Sebahat, hal-uş-ka $<$ hala, tet-uş-ka $<$ teyze, Hayr-uşka $<$ Hayriye, Hed-uş-ka $<$ Hediye.

\subsection{Belli bir kurala bağlı kalınmaksızın yapılan sevimli (hipokoristik) adlar}

Adların temel şekillerinden esinlenerek çoğunlukla kırpma ${ }^{15}$ yoluyla yapılan sevimli (hipokoristik) adların belli bir morfo-fonetik yapısının olduğunu söylemek veya böyle bir tespitte bulunmak mümkün değildir. Bu tip sevimli (hipokoristik) adlar herhangi bir kurala bağlı kalınmaksızın yapılırlar. Bazen iki veya daha çok heceli adın orta veya son hecesine hipokoristik yapma ekleri getirilerek yapılırlar. Bazı örneklerde de iki veya daha çok heceli adlarda baştaki bir ünsüz ve bir ünlü ile son hecedeki bir ünsüz alınıp arkasına yine hipokoristik yapma eklerinden biri getirilerek veya getirilmeksizin yapılırlar.

Örnek: Tsani $<$ Hasan, Dulo $<$ Abdullah, Dino $<$ Şerafettin / Hayrettin, Emi $<$ Elmas, Buşi $<$ Neb-uş / Buşka $<$ Neb-uş-ka $<$ Nebahat, Dano $<$ Ramadan, Mani / Manke $<$ Neriman / Keriman, Limi $<$ Selim, Tsufo $<$ Yusuf, Utsi $<$ Yusuf, Muyo $<$ Muhammet / Muharrem, Deti $<$ Saadet, İbadet, Mino $<$ Emine, Lido $<$ Mevlüde, Gipa $<$ Nagip, Nepo $<$ Zeynep, Zepo $<$ Zeynep, Meto $<$ Mehmet/Ahmet, Tafo $<$ Mustafa, Meri $<$ Meyrem (Meryem), Demo $<$ Adem, Yupi $<$ Eyüp, Keno $<$ İskender, Kif-o $<$ Hakif, Ziza $<$ Azize, Zade $<$ Zahide, Minka $<$ Emine, Biba $<$ Habibe, Fiza $<$ Hafize, Lilo $<$ Halil, Lido $<$ Mevlide.

\section{3. Çocuk konuşması taklidi}

Çocuk veya bebek konuşması taklidi yoluyla yapılan sevimli (hipokoristik) adlar iki türlüdür:

1. Bebeğin kişi adı veya akrabalık adını doğru telaffuz edemeyişinden ortaya çıkan ve önce aile içinde kabul görüp aile dışında da yaygınlık kazanmış olan sevimli (hipokoristik) adlar,

2. Kişiye önceden belirlenmiş bir sevimli (hipokoristik) adın bebek telaffuzundan değiştirilerek ortaya çıkıp aile içinde kabul gören ve daha sonra aile dışında yaygınlık kazanmış olan sevimli (hipokoristik) adlar. 
Çocuk konuşmasına dayanan bu sevimli (hipokoristik) adların nasıl olacağını tahmin etmek mümkün olmadığı gibi yapıldıktan sonra da aslında hangi addan veya sevimli (hipokoristik) addan geldiklerini belirlemek de zordur. Bu, ancak sevimli (hipokoristik) adın sahibi kişinin kendisi veya aile fertlerinin bilebileceği bir etimolojidir. Çevremizde etimolojisini bildiğimiz bu türden sevimli (hipokoristik) adlar vardır. Fikir vermesi açısından burada bir iki örneğe yer verilmiştir.

Amca $>$ aco $>$ caco, Refiçe (Refike $<$ Refika) $>$ Fiçe $>$ Çiçe, Züleyha $>$ Züli $>$ Lili, Hala $>$ Lâlâ, Fatme $>$ Fatuş $>$ Patuk gibi.

\subsection{Kişi adlarına küçültme ekleri getirilerek yapılan sevimli (hipokoristik) adlar}

Kosova Türklerinde sevimli (hipokoristik) ad üretme amacıyla sadece -cik küçültme eki kullanılır. Bu ekle yapılan sevimli (hipokoristik) adlar sahibinin boyuna atıfta bulunmak amaciyla yapılır.

Örnek: Ademcik, Alicik, Tasincik gibi.

Ancak bu tür sevimli (hipokoristik) adlar kişinin tam adından yapılabildiği gibi sevimli (hipokoristik) adına da -cik eki eklenerek yapılabilir.

Örnek: Ramocik(<Ramadan), Hüsicik (<Hüseyin) vb.

-cik eki ile hakaret anlamlı hipokoristikler de yapılır. Ancak bu hipokoristikler hakaret etmek amacıyla kullanıldıkları için kalıcı hipokoristikler değil, belli bir söylem içerisinde geçerler.

Örnek: caurcik (<gavur), domuzcik (< domuz), çüpekçik (<köpek) vb.

\section{Sevimli (hipokoristik) adlardan yapılmış soyadları}

Soyadından önce lakaplarla bilinen ve tanınan Türk insanları sevimli (hipokoristik) adları lakaptan sayarak zamanla bunlardan türetilmiş soyadlarını benimsemişlerdir. Kosova Türklerinde hipokoristik türetmesi olarak ortaya çıkmış soyadlarına örnek olarak Hamolar (<Hamit), Ramacik (<Ramadan), Cafçe (<Cafer) (Makedonca/Goranca hipokoristikten), Sülçe (<Süleyman) (Makedonca/Goranca hipokoristikten), Curcialo (<Gürcü Ali) sayılabilirler. Arnavutlar'da sevimli (hipokoristik) adlardan yapılış soyadlarının sayısı oldukça kabarıktır. Ancak bu çalışmanın Konusu Kosova Türkleriyle sınırlı olduğundan birkaç örnekle yetinilecektir: Demaj (<Adem), Demolli (<Ademoğlu), Jupolli (<Eyüpoğlu), Hajra (<Hayri, Hayrullah, Hayrettin), Meta (<Mehmet), Bajra (Bayram) vb.

\section{Sevimli (hipokoristik) adlara getirilen cinsiyet işaretleyicileri}

Sırp kültüründe eril ve dişil olmak üzere belli eklerle yapılan sevimli (hipokoristik) adlar Müslüman Arnavut kültüründe belli bir sistematik oluşturamamıştır. Sırpça sevimli (hipokoristik) adlar çoğunlukla ünlü ile biterler ve gramatikal cinsiyete bağlı olarak eril isimler için -o, dişil isimler için -ka eki tercih edilir. 
Sırpçada ad çekiminde seslenme (vokatif) hali vardır. Bu hali yapan ekler gramatikal cinsiyet, biyolojik ve sosyal (sosyal statü veya meslek) cinsiyete bağlı olarak eril, dişil ve nötrdür. Kişi adları, sıfatları, unvan ve sanları biyolojik ve sosyal cinsiyet kategorisini içerirler. Dolayısıyla kişilere seslenilirken adların seslenme (vokatif) halleri kullanılır. Arnavutçada böyle bir hal yoktur. Bu nedenle Kosova Arnavutçasında kişilere seslenilirken $o$ (Demiraj, 1973: 434) ve oy seslenme ünlemleri kullanılır. Kosova Türkleri de seslenme veya hitap esnasında bu ünlemleri kullanırlar. Örneğin: $O$ Beyto! örneğinde seslenilen kişi erkektir ve asıl adı Beytullah'tır. Oy Bato! örneğinde ise seslenilen kişi kadın cinsiyetine mensup olup asıl adı Bahtişah’tır. Kosova Türklerinde hitap doğrudan ad veya sevimli (hipokoristik) adla yapılabildiği gibi, hitap edilen kişinin yaşına bağlı olarak ad veya sevimli (hipokoristik) adların arkasına bir hitap adı veya sevimli (hipokoristik) adı eklenerek de yapılır. Beyto aco, Beska tada ${ }^{16}$, Patuk ${ }^{17}$ aba.

Kosova Türklerinin köylerde ve Arnavut kültürünün daha baskın olduğu kasabalarda yaşayanları Arnavut kültüründen etkilenilerek Müslüman Arnavutların tercih ettikleri seslenme adlarını benimsemişlerdir. Bu sevimli (hipokoristik) adlar bazen Boşnakların kullandıklarıyla benzerlik arz ederler. 1999 Kosova savaşından önce Sırp kültürünün baskın olduğu şehirlerde bu kültüre duyulan özentiden Sırpçadaki sevimli (hipokoristik) adların aldıkları ekler daha çok tercih edilmiştir. Ancak bu, belli bir morfo-fonetik kurala uyulmaksızın yapılan sevimli (hipokoristik) adlar için geçerli bir kural değildir.

\section{Sonuç}

Adların kısaltılmış veya başka şekilde değişime uğrayarak bazı ekler getirilmek suretiyle ortaya çıkan şekilleri için kısaltma, küçülme tasgir, tahbib gibi terimlerden daha kapsayıcı bir anlam ifade eden sevimli (hipokoristik) ad teriminin kullanılması daha isabetli olur. Sevimli (hipokoristik) ad yapmak için kullanılan ekler, kökenine bakılmaksızın, Rumeli Türkçesinin yapım ekleri çerçevesinde ele alınmayı gerektirir.

Kosova'da genel anlamda kapsamlı kişi adları (antroponimi) ve soyadları (patronimi) çalışmaları henüz yapılmış değil. Kişi adları ve soyadları ile ilgili yapılacak ve özellikle buna ilişkin etimolojiyle alakalı çalışmalarda sevimli (hipokoristik) ad kavramı, olgusu ve yapılış şeklinin dikkate alınması önemlidir.

Bu çalışmada üzerinde durulmamakla birlikte Kosova'da kişi adlarından veya bunların sevimli (hipokoristik) şekillerinden yapılmış olan coğrafi adlar da mevcuttur. Dolayısıyla bu olgu dikkate alınmaksızın onomastik alanında yapılacak olan etimolojik tahliller ya yanlış yöne sevk edecek ya da eksik kalacaktır.

Bu çalışma ile hem Kosova'da ve özelde Kosova Türklerinde var olan bir folklorik unsura işaret etmiş olmak hem de adbilimi (onomastik) ile kişi adları (antroponimi) ve soyadları (patronimi) alanına bir katkı sunmak amaçlanmıştır. 


\section{Notlar}

$1 \quad$ Bkz. (İmer ve diğerleri, 2013, s. 228)

2 Uluslararası Onosmastik Bilimleri Kurulu terim listesindeki tanım "unofficial expressive form of a name morphologically derived from the personal name" https://icosweb.net/ (ET: 20.04.2020)

3 https:/www.dictionary.com/browse/hypocoristic?s=t;https://www.etymonline.comsearch?q=hypocoristic (ET: 17.04.2020)

$4 \quad$ Bkz. (İmer ve diğerleri, 2013, s. 177)

5 https:/www.britannica.com/topic/hypocoristic-name: Hypocoristic forms of names are those that are used in familiar, friendly, or intimate situations (usually shortened or otherwise modified)-e.g., Tom for Thomas, Jim for James. Some of these forms are also used as given names, particularly in the United States. (ET: 07.08.2020)

6 https://sozluk.gov.tr/ (ET: 10.01.2020)

7 http://lugatim.com/s/lakap (ET: 10.01.2020)

$8 \quad$ https://sozluk.gov.tr/ (ET: 10.01.2020)

9 http://lugatim.com/s/mahlas (ET: 10.01.2020)

10 Bu çalışmada Batı Balkanlar'da konuşulan Sırpça, Boşnakça, Hırvatça, Karadağlıca, Makedonca gibi diller ile Kosova Türkçesinin ilişkide olduğu Goranca, Torbeşçe lehçeler düşünülmektedir.

11 Bu örneğin türetilme şekli için bkz. Şenel (2010); Türkiye'de kullanılışına ilişkin toplumdilbilimsel ve ruhdilbilimsel koşullar için bkz. İsa Sarı, Türkçede Küçültme, 2020, Nobel.

12 Ali Ulvi Elöve, Jean Deny’nin Türk Dil Bilgisi adlı eserini 1941 yılında Türkçeye çevirerek çeviri esnasında kendi açıklamalarını dipnotlarla ilave etmiştir. http://teis.yesevi.edu.tr/madde-detay/elove-ali-ulvi web sayfasındaki yaşamöyküsüne göre 1881 yılında Selanik’te doğmuş ve bir süre Manastır'da bulunmuştur. 31 Mart Vakası (13 Mart 1909) üzerine İstanbul'a yürüdüğü belirtilmektedir. Elöve, belirttiği tahbib şekillerini Slavcanın (Bulgarca / Makedonca veya Sırpça) da konuşulduğu Manastır'da bulunduğu süre zarfında tespit etmiş olma olasılığı vardır. Zira Slavcaya has bu ek örneklerin Selanik’te tespit edilmiş olma olasılığı çok düşüktür. Her halükarda bu tespit, Batı Rumeli Türklerinde bu geleneğin 1909 yılından önce var olduğunun bir delilidir.

13 Prizrenli bir öğrencimizin adı.

14 Gül- ile başlayan kişi adlarının çoğu bu şekilde yapılır.

15 Bkz. (İmer ve diğerleri, 2013, s. 177)

16 Prizren'de ăgabey, amca seslenme adı olarak kullanılır.

17 Bebek konuşması yoluyla Fatime $>$ Fatuş $>$ Patuk şeklinde gelişmiş bir hipokoristik ad.

\section{Kaynakça}

Abdürrahman, V. (2004). Türklerin ad koyma gelenekleri üzerine bir inceleme. Millî Folklor (61), 124-133.

Aksan, D. (2000). Her yönüyle dil ana çizgileriyle dilbilim. 3 TDK.

Barić, E., Lončarić, M., Malić, D., Pavešić, S., Peti, M., Zečević, V. ve Znika, M. (1997). Hrvatska gramatika-II. promijenjeno izdanje. Školska knjiga.

Dzurovic, S. (2009). Derivaciono gnezdo lekseme kuça. Tvorbeno-Semantiçka Analiza. Nasledje- $\mathrm{Ca}$ - 
sopis za Knjizevnost, Umetnost i Kulturu, Godina.I (1), 83-103.

Ćužić, T. (2017). Imenska deminucija u hrvatskome i makedonskome jeziku. Jezikoslovlje, 2 (18), 227-243.

Demiraj, S. (1973). Morfologjia historike e gjuhes shqipe. Universiteti i Tiranes.

Demiraj, S. (2002). Gramatika e gjuhes shqipe 1. Akademia e Shkencave e Shqiperise.

Deny, J. (2012). Türk dil bilgisi. (A. Benzer, Düz.), (A. U. Elöve, Çev.) Kabalc1.

Dzogoviç, A. (2002). Dijalektalne i zavicajne govorne specifinnosti u epu zenidba smailagic mehe avda medzedovica. Casopis za Proucavanje, Prezentaciju i Zastitu Kulturno-Istorijske Bastine Muslimana-Bosnjaka, 17-84.

Halilović, S., Tanović, I. ve Šehović, A. (2009). Govor grada Sarajeva i Razgovorni Bosanski Jezik. Slavistički Komitet.

İmer, K., Kocaman, A., Özsoy, A. S. (2013). Dilbilim sözlüğü. İstanbul: Boğaziçi Üniversitesi.

Karahan, L. (2009). Türkçede dini anlamlı bazı kişi adlarını ekle değiştirme geleneği. Dil Araştırmaları (4), 17-24

Nestor, V. (2004). Makedonsko leksicko zboroobrazuvacko vlijaniya vrz Albanskiot Jazik. Plenarna Sesija ASNOM Makedonskata Kultura i Istorija 2004-Lingvistika, 363 - 372.

Piper, P. ve Klajn, I. (2014). Normativna gramatika srpskog jezika. Matica Srpska.

Sarı, İ. (2020). Türkçede küçültme. Ankara: Nobel.

Škaljić, A. (1966). Turcizmi u srpskohrvatskom jeziku. Svjetlost.

Stanojcic, Z. ve Popovic, L. (1981). Gramatika Srpskoga Jezika. Naucna Knjiga.

Xhuvani, A. ve Çabej, E. (1962). Prapashtesat e gjuhës shqipe. Instituti i Historisë e Gjuhësisë.

Zakar, V. (2011). Akumuliranje na deminutivnite formanti vo makedonskiot razgovoren jazik. Croatica et Slavica Iadertina. 7(2), 403-411.

\section{Elektronik kaynaklar}

Bosanac, S. (2009). Cognitive approach to the study of diminutives: The semantic background of croatian diminutives. Sveučilište u Zagrebu Filozofski Fakultet, Erişim tarihi: 17.07.2012, http://ffzg. academia.edu/SinisaBosanac/Papers

Dictionary.com, Erişim Tarihi: 17.04.2020, https://www.dictionary.com

Encyclopedia Britannica, Erişim Tarihi: 07.08.2020, https://www.britannica.com

Güncel Türkçe Sözlük, Erişim Tarihi: 10.01.2020, https://sozluk.gov.tr/

International Council of Onomastic Sciences. (tarih yok). International Council of Onomastic Sciences (ICOS). Erişim Tarihi: 20.04.2020, https://icosweb.net/wp/wp-content/uploads/2019/05/ICOSTerms-en.pdf

Kubbealtı Lügati, Erişim Tarihi: 10.01.2020, http://lugatim.com 
Makišova, A. (2012). Deminutivi u Slovačkom i Srpskom Jeziku. Univerzitet u Novom Sadu Fiozofski Fakultet, Erişim Tarihi: 18.04.2012, http://www.ff.uns.ac.rs/stara/elpub/susretkultura/92.pdf

Online Ethymology Dictionary, Erişim Tarihi: 17.04.2020, https://www.etymonline.com

Şenel, M . (2010). Kes-Kopyala-Yapıştır; Yeni Kelime Türet . Türk Dili Araştırmaları Yıllığ - Belleten , 57 (2009/1) , 99-110, Erişim Tarihi: 17.11.2020, https://dergipark.org.tr/tr/pub/belleten/issue $/ 45450 / 570485$

Tunçdemir, C. (2015). Amerikan isimlerinin kısaltmaları, Erişim Tarihi: 24.04.2020, http://amerikabulteni.com/2015/10/31/amerikan-isimlerin-kisaltmalari/

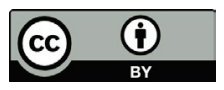

Bu eser Creative Commons Atıf 4.0 Uluslararası Lisansı ile lisanslanmıştır.

(This work is licensed under a Creative Commons Attribution 4.0 International License). 